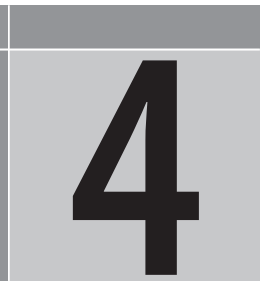

\title{
Customisation and desirable characteristics of a standard method of measurement for building works in Ghana
}

\author{
Gabriel Nani ${ }^{1}$, Peter J. Edwards ${ }^{2}$, Theophilus Adjei-Kumi ${ }^{1}$, Edward Badu ${ }^{1}$, Peter \\ Amoah $^{1}$ \\ ${ }^{1}$ KNUST, Kumasi, Ghana \\ ${ }^{2}$ School of Property, Construction and Project Management, RMIT University, \\ Melbourne, Australia
}

\section{ABSTRACT}

This paper reports a study that identified and categorised the modifications to the 5th Edition of the British Standard Method of Measurement (SMM5) of building works in Ghana. Typical modifications involved 'cost insignificant items', 'minor labour items', 'custom units of measurement', 'method related items', 'combinable items', 'subordinate items', and 'items of minor informative impact'. It was also observed that the desirable characteristics/ qualities of standard methods of measurement (SMM) of building work were noteworthy, since they provide insight into the nature of a SMM required for the construction industry in Ghana.

The research reviewed available literature, various SMMs and bills of quantities (BQs). The relevance of the modifications and SMM characteristics identified was confirmed by a survey of the opinions of professional quantity surveyors conducted through a carefully designed questionnaire. Inferences from the opinion survey formed the basis for grouping both SMM modifications found and the desired qualities of a SMM for Ghana.

Survey respondents confirmed all the identified modifications to the British SMM, except for the elimination of items of minor informative impact. It was held that all information was relevant in measurement. Desirable characteristics of a SMM were rated in decreasing order of relevance as: easy location of items; cost significance; simplicity; thoroughness; ease of cost analysis; good practice; conciseness; adoptability; precision; industry practice; stakeholders' opinion; custom classification; regional relevance; and inclusion of jargon. It was noted that the relevance of these characteristics may vary form one region to the other as a result of technological, cultural and legal differences. However, the desired SMM characteristics were recommended as fundamental in developing an appropriate SMM for Ghana.
Keywords: Building measurement, standard methods, quantity surveying, construction industry

\section{INTRODUCTION}

This paper reports on research aimed at identifying how standard methods of measurement (SMMs) of building work have been customised in Ghana, and at exploring the essential characteristics expected in SMMs. The research involved review and discussion of SMMs generally and identification of the documents used in Ghana. The practice of building measurement in Ghana was analysed by examination of typical Bills of Quantities (BQs), and this analysis helped to identify the modifications to the SMMs in use. The modifications were categorised according to their underlying principles of measurement. Confirmation of the findings was obtained through an opinion survey of local quantity surveyors in Ghana.

\section{STANDARD METHODS OF MEASUREMENT}

Standards for quantifying and describing proposed construction works (usually referred to as a "Standard Method of Measurement of Building Work" or "SMM") are found in most British Commonwealth countries and are used mainly by professional quantity surveyors to provide a uniform and commonly accepted basis for the preparation of "bills of quantities" as tender documents for new building projects. Earley and Gould (2004) describe the SMM as: 'a formal document setting out conventions for defining the nature of construction works, how the work is measured or taken off and quantified'. An examination of the function of the SMM indicates that it is similar to a language which provides meaning (what is included or excluded) to quantified information that is prepared in accordance with its rules.

SMMs are most often applied in the preparation of BQs for tendering purposes, usually where the BQs form part of the contract. Brook (2004) indicates that there is a school of thought that describes a SMM as 
purely a set of rules indicating how work is measured and what is to be included in the description of a measured item. He points out that a SMM is neither a method for producing bills nor an aid to pricing bills. Contrary to this school of thought, most standard methods of measurement provide general rules for preparing BQs and estimating (RICS and BEC, 1988 - General Rule No.1; AIQS, 2001 Introduction, general rules and recommendations No.2; SPRING Singapore , 2002 - Guidance notes and general principles 2.4.1, etc).

The use of SMMs is widespread. A global survey by the Building Cost Information Service (BCIS) on behalf of the Royal Institution of Chartered Surveyors (RICS) identified 32 SMMs in existence (RICS, 2003); while Mills et al. (2006) identified 44 documents spread over 32 countries. Many SMMs are updated editions or amended versions of the UK's SMM5 and SMM7 editions, published by the Royal Institution of Chartered Surveyors ( RICS and NFBTE, 1964; BCIS, 2004; Brook, 2004; Foster, 2005; Jaggar et al., 2001; Morledge and King, 2005; Wood and Kenley, 2004) .

\section{SMMS IN CURRENT USE IN GHANA}

A global survey (RICS and BEC, 1988) identified the use of the British $7^{\text {th }}$ Edition of the Standard Method of Measurement (SMM7) in Ghana, but local surveys conducted in Ghana in 2003 and 2004 found that SMM7 was little used (19\% usage) compared to the earlier SMM5 edition (65\% usage) (Djakumah, 2004; Dodoo, 2003; Hanson, 2003; Laate, 2003). The latter survey was conducted with quantity surveyors who had been in practice for about 10 years and who were members of the Ghana Institution of Surveyors (GhIS). Respondents were asked to indicate the SMM they normally used in carrying out measurement of building works. The RICS global survey may have been biased by respondents who were members of the RICS but resident in Ghana. SMM5 has remained the most commonly used SMM in Ghana until July 2007, when GhIS requested all its members to use SMM7 (Nani and Adjei-Kumi, 2007). It has also been found that the Civil Engineering Standard Method of Measurement, $3^{\text {rd }}$ edition (CESMM3) published by the Institution of Civil Engineers (ICE, 1991) is used in the measurement of civil engineering works in Ghana.

Analysis of the course syllabi for tertiary quantity surveying students in Ghana reveals that SMM7 is the prescribed document for training students. This might also explain the 'global survey' finding. Disparity in practice and training can cause confusion for new quantity surveyors who then have to learn the application of SMM5 (which varies appreciably from SMM7). The high usage of SMM5 (which was published in 1964, replaced by SMM6 and subsequently by SMM7) found in the local surveys, despite the fact that SMM7 was introduced into academic syllabi in 1993, indicates a low level of assimilation of change in the construction industry in Ghana. It may also be an indication that SMM5 was more suitable in Ghana.

\section{RATIONALE FOR DEVELOPING SMMs}

The development and revision of SMMs in the construction industry is driven by various factors, including:

- The quest for uniformity in measurement.

- The need to match standard methods of measurement with the development of new techniques in the construction industry.

- The need to clarify and simplify standard rules of measurement.

- The need to satisfy certain construction industry stakeholders (e.g. contractors' need for approximate quantities).

- The need to conform to national specifications and prevailing conditions of contract, and international conventions (e.g. the introduction of SI metric system in the 1960s).

- The requirement to conform to national classification systems such as 'common arrangement of work sections' which affect the format of tender documents such as $B Q s$.

The above factors were derived from analysis of the prefaces of SMMs reviewed (ACE and RICS, 1984; AIQS and MBFA, 1980; ASAQS, 1977; ASAQS, 1999; NIQS, 2003; RICS and NFBTE, 1964; Singapore Institute of Surveyors and Valuers, 1986). Early practices (before 1922) of measurement of building works in the United Kingdom was characterised with diversity, variation in local custom or idiosyncrasies, doubtful qualification of quantity surveyors and disputes in actual measurement of buildings. The British response to this problem was the introduction of the first edition of the RICS SMM of Building Works in 1922. The Standard was intended to ensure accuracy and introduce uniformity into measurement of building works. Subsequent editions clarified and amplified existing rules to 
conform to new conditions of contract, technological developments, changes in the method of construction and new systems of classifications (RICS and BEC, 1998).

Later, international principles of measurement of building work and a SMM of industrial engineering construction were developed to obtain international uniformity in measurement in the area of industrial engineering construction. These reasons also hold for the development of other SMMs such as the Australian Standard Method of Measurement of Building Works, East African Standard Method of Measurement in Kenya, Indian Standard Method of Measurement of Building Works, the Civil Engineering Standard Method of Measurement, the South African System of Measurement of Building Works and the Nigerian Building and Engineering Standard Method of Measurement. While these are national standards, other standards such as the Rider Hunt System of Measurement for Construction Quantities, and Measurement Rules for Contractors Quantities were developed by professional quantity surveying firms for in-house use (even where existing national SMMs were available).

It can be deduced that the development of SMMs is motivated by factors such as: technology change; strength and influence of professional institutions; local, national and international professional practice and cultures: commercial industry requirements; and legal precedence/requirements in building procurement.

Technological developments introduce new techniques and methods of construction, new materials and equipment which can affect the way construction work is measured. For example, electrical installations were introduced as an additional section into the $4^{\text {th }}$ edition of the British SMM after a move for the adoption of BQs for services installations began in the UK in the 1960s. Similarly the concept of method-related charges was introduced in CESMM3, to cater for the more mechanised methods of construction being developed for civil engineering works. It was important, for example, for earthworks contractors to know (when tendering) of situations where space or depth restrictions might preclude the use of large capacity mechanical excavators. Also influencing the development of SMMs are national or organisational policies (i.e. countries or companies may decide arbitrarily how they want particular work items measured). Policies for the adoption of unified classifications or the implementation of particular information and communication systems may drive the development of SMMs. Cultural issues such as traditions, local jargon, etc. embodied in existing practices may need to be acknowledged. Legal requirements and legal precedence (litigation) affecting building procurement systems might have to be recognised. These factors underlie the amendments made to UK SMM5, when it was adopted in Ghana.

\section{CRITIQUES OF SMMS}

SMMs are not without their critics. They have been criticised for their excessive complexity, lack of consideration for construction practice, failure to meet pricing and stakeholder requirements, and for inadequate industry consultation during their development stage (Goh and Chu, 2002).

Morledge and King (2005) found that specialist sub-contractors in UK were not satisfied with the information provided in BQs prepared in accordance with SMM7. The specialists' concerns indicated inadequacy of relevant $B Q$ item detail and inability of the measured items to adequately represent real costs. Foster (2005) elaborated this point by intimating that the rules of measurement for electrical and mechanical works are out of tune with the actual programme of works for these installations. He illustrated this point with an example where the rules of measurement (British SMM7 clause Y61.19 and SMM5 clause T19) prescribe the measurement of a lighting fitting as a composite item which includes the light fitting together with its cabling and conduiting (containment). These actually represent three separate activities which occur at different stages of the project. The principles of progressive reimbursement to the electrical sub-contractor through interim valuations of work in progress would require that the various lighting components should be separately measured (or the composite price would have to be decomposed for progress payments). This principle is however neglected by most SMMs, suggesting that they are heavily biased towards tendering rather than administrative cost control purposes.

A BCIS/RICS survey (2004) found that $15 \%$ of contractors frequently amended (customised) SMM7 to suit their own purposes, while $31 \%$ of estimators indicated there are areas where the SMM7 did not match their estimating (pricing) conventions. Only $10 \%$ of consultants, $4 \%$ of contractors and $3 \%$ of clients were opposed to any changes being made to SMM7. The comments of survey respondents generally 
indicated a lack of confidence in the suitability of SMM7 for its purpose. Dissatisfactions identified by the survey included:

- Misinterpretation of SMM7 Rules, resulting in frequent misunderstanding between contracting parties. Simplification of measurement rules was suggested.

- The unnecessary complexity of SMM7.

- Lack of focus in SMM7 on important factors that influence price, such as method of construction or local estimating conventions.

- Confusion about the classification structure of SMM7, which respondents thought was inadequate. They believed that classification according to trade sections was better than the SMM7 common arrangement of works sections. The significance of this complexity is that it results in difficulties in locating measurement rules in SMM7 for particular work items or combinations of items.

Jaggar et al. (2001) also criticised SMM7 for paying little attention to the contractors' needs in terms of following processes of construction. This problem is not unique to SMM7 as Wood and Kenley (2004) found similar deficiencies in the Australian SMM, noting that: "... not one participant - quantity surveyors, contractors and subcontractors - believed they were adequately consulted or represented in the production of the Australian Standard Method of Measurement of Building Works". This has resulted in the SMM losing its potency in Australian construction industry. The need for a simplified SMM without unnecessary detail was also elaborated by Mills et al. (2004) who recommended the South African SMM to the AIQS and RICS as a guide for subsequent revision of their respective SMMs. The simplified nature of the South African System of Measurement is an attempt to satisfy the many stakeholders in the construction industry.

Criticism of SMMs ranges from legal issues (i.e. misinterpretations and complexities that could result in disputes and litigation); technological issues that relate to methods of construction and simplification of the measurement process; through to cultural issues that require adequate consultation with stakeholders in order to understand and incorporate sound traditional practices as well as promote the use of a SMM developed. These critiques set the agenda for an investigation into the qualities desired of a typical SMM.

\section{RESEARCH METHODOLOGY}

The research involved literature review, categorisation of modifications to existing SMM adopted in Ghana, and expert opinion survey. Generally, the literature review provided an insight into the topic. However, it also presented a background to classify the types of modification to UK SMM5, which have been adopted in Ghana. The literature review also gave an overview of the inadequacies of existing SMMs, which then became a basis for deriving the desirable characteristics of a SMM.

In categorising the SMM5 modifications extant in Ghana, 40 BQs were obtained from 20 of the 43 quantity surveying firms registered with the Ghana Institution of Surveyors (GhIS) as at 2007. The firms were randomly sampled from a list issued by the GhIS. This ensured that the investigation represented the current practice of quantity surveying firms in Ghana. Expert opinions of quantity surveyors in Ghana were sought on the relevance of the various modifications and the essentiality of the desirable SMM characteristics to the Ghanaian construction industry. The quantity surveyors were all members of GhIS. Their opinions were expressed by rating answers to questions in the survey instrument on a 1-5 ordinal Likert scale. On this scale, ' 1 ' represents 'strongly acceptable' and ' 5 ' represents 'strongly unacceptable'.

A total of 250 questionnaires were sent out to quantity surveyors for their expert opinion. This sample size was obtained using the relation below. The use of this relation was based on the formula suggestion of Kumar (1999), and Clarke and Cook (1998):

$$
n=\frac{\left(Z_{0.05}\right)^{2} p(1-p)}{E^{2}}
$$

Where:

$n$ represents the sample size.

$Z_{0.05}$ represents $z$-value from the normal distribution table at $95 \%$ significance level.

$p$ represents the proportion expected to express the same opinion. Similar investigations in Ghana by Djakumah (2004), Dodoo (2004) and Laate (2003), suggests that more than $50 \%$ of quantity surveyors would express similar opinion on SMM related investigation. $p$ is therefore taken as 0.5 , since this figure also provides the highest sample size obtainable.

E represents the standard error, which was assumed as 0.1 for this survey. Based on Kumar's (1999) suggestion, this error margin

Considering the above formula, a sample size of 96 was obtained. However, research in 
Ghanaian construction industry by Badu et al (2004), Danso and Akyempim (2004) and Hohoabu (2003) indicated an average of $40 \%$ response rate for hand-delivered questionnaires. Since, the questionnaire for this survey was intended for hand-delivery, the sample size was modified as below and approximated to 250 :

$$
n^{\prime}=\frac{96}{0.4}=240
$$

The quantity surveyors were sampled from consulting quantity surveying firms, contractor firms, and through a process of snowball sampling. All 43 GhIS registered quantity surveying firms were targeted in the sampling process. Construction firms registered with the Ghana Government Ministry (Ministry of Works, Housing and Water Resources), were also targeted in the snowball sampling process.

\section{FINDINGS: MODIFICATIONS TO SMM IN GHANA}

Examination of the $40 \mathrm{BQs}$ revealed the use of modified version of the British SMM5. These modifications were found in the preamble sections of nearly $90 \%$ of sample BQs examined and reflected in the measured quantities. The modifications were similar throughout the sample; hence they are regarded as universally adopted modifications (or local measurement practice) in Ghana. Some modifications were observed in the measured items in bills of quantities but not referred to in the preambles sections to those BQs (most SMMs for building work require departures from their measurement principles/rules to be flagged in the preambles sections of the concomitant BQs).

The modifications found cover 141 clauses of SMM5 (spread over all work sections and involving major work items in Ghana). Analysis of the modifications indicates that nearly half $(46 \%)$ involved minor labour items or materials which were not separately measured but deemed to be included in the descriptions of the major items in which they occurred. Some measurable items were combined and in other instances certain descriptors were removed as if they were cost insignificant. The clear intention of the modifications was to keep the bills of quantities concise. Other modifications included changes in the units of measurement for some work items, to reflect the perceptions of the local industry about how those items should be represented in BQs. These changes affected mainly superficial items of work (i.e. plasterwork and other floor, wall and ceiling finishes as well as painting and decorating). The modifications identified in the sample BQs are summarised as follows:

1. Elimination of items of minor cost significance;

2. Elimination of minor labour items;

3. Changes to units of measurement;

4. Association of some items with a major item, arising as a result of contractors' selection of construction method;

5. Combination of items where separation would have insignificant impact on cost;

6. Elimination of items that are most often measured together with a major item;

7. Elimination of descriptors that have minor informative impact on pricing.

Sections of SMM5, which were most modified included: Plasterwork and other Floor Wall, Ceiling and other Finishings; Joinery; Concrete Work; Blockwork; and Painting and Decorating. The un-modified sections included Preliminaries, Demolition and Alteration, Piling, Underpinning, Rubble Walling, Masonry, Asphalt Work, Structural Steelwork, Glazing, and Fencing. Absence of modification could be due to the more specialised nature of these types of work; such that a local customary practice has not yet developed.

\section{RESULTS OF OPINION SURVEY: MODIFICATIONS TO SMM5}

Out of a target of 250 Quantity Surveyors, 111 responded (i.e. is a response rate of $44 \%$ ). The respondents were greater than the calculated required sample size (96), hence the response was assumed to be adequate. The modal and the mean values of the rated opinions were calculated. Statistical 'p-values' were determined to assess the probability of differences between the respondents' opinions occurring by chance. Summary of the analysis is presented in Table 1.

Respondents modally agreed with the acceptability and relevance of all the local practices listed except modification type No.7 (i.e. ignoring descriptors of minor informative impact). However their acceptance of the first two practices was stronger as the mean ratings skewed towards strong acceptability. Between $89 \%$ and $92 \%$ of respondents agree or strongly agree with the acceptability of the first two listed practices respectively. A Z-Test yielded a p-value of zero, which suggests that it is almost $100 \%$ certain that quantity surveyors will always accept this practice. 


\begin{tabular}{|c|c|c|c|c|c|c|c|}
\hline & \multicolumn{7}{|c|}{ Modifications to SMM5 } \\
\hline & 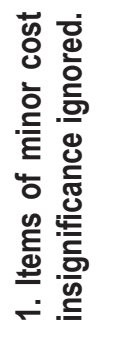 & 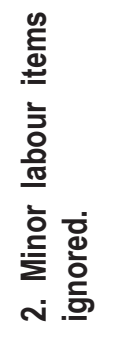 & 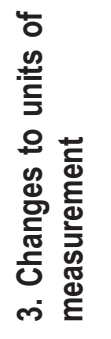 & 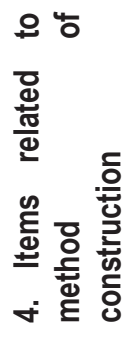 & 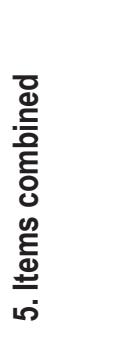 & 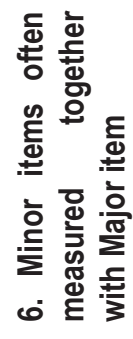 & 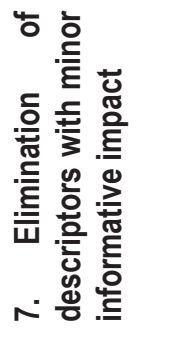 \\
\hline Mode & 2 & 2 & 2 & 2 & 2 & 2 & 4 \\
\hline Modal frequency & 54 & 60 & 51 & 60 & 54 & 48 & 48 \\
\hline Total Response & 111 & 111 & 111 & 111 & 111 & 111 & 111 \\
\hline$\%$ Mode & $49 \%$ & $54 \%$ & $46 \%$ & $54 \%$ & $49 \%$ & $43 \%$ & $43 \%$ \\
\hline Mean & 1.865 & 1.946 & 2.081 & 2.162 & 2.432 & 2.622 & 3.162 \\
\hline $\begin{array}{l}\text { Interpretation of } \\
\text { mode }\end{array}$ & accept & accept & accept & accept & accept & accept & unacceptable \\
\hline p-value & 0.00 & 0.00 & 0.00 & 0.00 & 0.00 & 0.01 & 0.98 \\
\hline
\end{tabular}

Table 1 Acceptability of Modifications to SMM5 in Ghana

The respondents also modally agreed with the acceptability of modifications types No.3, No.4, No.5, and No.6 as in Table 1; but the general agreement to these practices skewed towards un-decidedness. Further, $84 \%, 84 \%, 78 \%$ and $65 \%$ of respondents respectively significantly agree with these modification types respectively. A Z-Test yielded $p$-values of approximately zero except for modification type No.6 which has a p-value of 0.006 . The $p$-values for all four practices under consideration here are less than the critical $p$ value (i.e. $5 \%$ significance level), hence it is considered that the respondents significantly agree with these modification types. Conversely, $57 \%$ of the respondents disagreed with the acceptability of modification type No.7', though this disagreement skewed towards undecidedness rather than strong disagreement. A Z-Test of the response yielded a p-value of 0.98 which is greater than the critical value $(0.05)$. It is therefore inferred that the respondents are in disagreement with the acceptability of this type of modification. This opinion suggests respondents value all measurement information, irrespective of its significance.

In summary, all the modifications were acceptable to survey respondents except 'the elimination of descriptors that have minor informative impact on pricing'. It was evident from the analysis that respondent quantity surveyors pay attention to cost significant items, remove unnecessary labour items, where necessary use units of measurement convenient to the industry, and are as brief as possible in their written descriptions. The 'Elimination of descriptors with minor informative impact' was unacceptable to respondents, because items were expected to be sufficiently described to prevent any ambiguity. Examples of each type of modification are presented in Table 2. This result confirmed the position of SMM critiques reviewed in the literature, especially with regard to cost significant items, and simplification of measurement. These categories of modification therefore provide some insight into the various aspects to consider in addressing the current shortfalls of SMMs

\section{RESULTS OF OPINION SURVEY: ESSENTIAL QUALITIES OF A SMM}

The essential qualities for a SMM were deduced from the rationale underlying SMM development, review critiques and the principles behind the modifications of SMM5 in Ghana. Other sources which contributed to the identification of these qualities include arguments presented by authors such as Edwards and Edwards (1995) in Australia, Horner and Zakieh (1996) in United Kingdom, and Tas and Yaman (2005) in Turkey. These authors based their argument on the fact that the use of cost significant and characteristic items in classification would simplify SMMs. Consequently, the essential qualities of SMM deduced from literature and analysed in Table 3 include: 


\begin{tabular}{|c|c|}
\hline Type of Modification & Examples of Items \\
\hline $\begin{array}{l}\text { 1. Items of minor cost } \\
\text { insignificance ignored. }\end{array}$ & $\begin{array}{l}\text { Making good work contractually disturbed in order to carryout other } \\
\text { work such as making good concrete work connected with holes etc. } \\
\text { Pipes in branches of less than } 3.00 \text { metres long not measured } \\
\text { separately. }\end{array}$ \\
\hline $\begin{array}{l}\text { 2. Minor labour items } \\
\text { ignored. }\end{array}$ & $\begin{array}{l}\text { Trimming of surfaces of excavation. } \\
\text { Cutting of grooves, holes for pipes, mortises, raking cutting, notching } \\
\text { around obstructions etc. } \\
\text { Crossed grain and stopped end labours to wood for carpentry and } \\
\text { joinery. }\end{array}$ \\
\hline $\begin{array}{l}\text { 3. Changes to units of } \\
\text { measurement. }\end{array}$ & $\begin{array}{l}\text { Finishing and painting work in narrow widths (i.e. not exceeding } \\
300 \mathrm{~mm} \text { ) are measured in superficial units instead of linear units as } \\
\text { prescribed by SMM5 and SMM7. }\end{array}$ \\
\hline $\begin{array}{l}\text { 4. Item quantities and } \\
\text { descriptions related to } \\
\text { method of construction. }\end{array}$ & Planking and strutting measured (earthwork support). \\
\hline 5. Items combined. & $\begin{array}{l}\text { Casings (formwork) to beams, lintels and stanchions, combined with } \\
\text { beams, and columns respectively. } \\
\text { Mullions, transoms, jambs, heads and sills for windows and doors } \\
\text { which can be combined and measured together as frames. } \\
\text { Finishes in narrow surfaces to walls, ceilings, and floors are grouped } \\
\text { together rather than measured separately. } \\
\text { Finishes to isolated columns are grouped with walls; while work to } \\
\text { isolated beams is grouped with beams. }\end{array}$ \\
\hline $\begin{array}{l}\text { 6. Minor items often } \\
\text { measured together with } \\
\text { major item. }\end{array}$ & $\begin{array}{l}\text { Excavation of drainage trenches is deemed to include backfill, } \\
\text { ramming and earthwork support. } \\
\text { Manholes, soakaways, cesspits, and septic tanks are also deemed to } \\
\text { include building in ends of pipes. }\end{array}$ \\
\hline $\begin{array}{l}\text { 7. Elimination of descriptors } \\
\text { with minor informative } \\
\text { impact. }\end{array}$ & $\begin{array}{l}\text { Thicknesses of foundation concrete stated where it is measured in } \\
\text { cubic units. }\end{array}$ \\
\hline
\end{tabular}

Table 2 Examples of modifications found in sample BQs

- Consideration for cost significant items.

- Conciseness of SMM and the resulting bills of quantities.

- Consideration for existing industry practice.

- Preciseness of SMM and the resulting bills of quantities.

- Consideration for stakeholders' opinion.

- Consideration for cost analysis.

- Good practice.

- Simplicity.

- Ease of locating rules.

- Regional (country or organisation) relevance.

- Thoroughness of SMM and resulting BQ descriptions.

- Allowance for custom classifications.

- Consideration for local jargon.

- Flexibility of SMM for adoption to major procurement systems.

Various statistical analyses were conducted to aid the interpretation of the survey responses. These statistics include: mode, mean and the significant test ( $p$-value) at $5 \%$ level $(p$-value $=$ 0.05).

As indicated in Table 3, all except 'custom classification', 'regional relevance' and the 'inclusion of local jargons', had modal ratings of "highly- or very relevant". 'Custom classification' and 'regional relevance' achieved a modal rating of "moderately relevant", while 'inclusion of local jargon' was rated as "rarely relevant". At least $92 \%$ of respondents rated the properties as "significantly relevant". Fewer respondents scored 'regional relevance' as "significantly relevant" while only $54 \%$ rated the use of local jargon as "significantly relevant" to a SMM. The mean score for each property also followed a similar pattern as the modal values, while the average deviation was less than 1 for all properties except 'inclusion of jargons'. This implies that the respondents had generally accepted all characteristics as relevant to developing a SMM. 
Though the survey respondents were consistent in respect of the relevance of the desirable characteristics, there were varied opinions on the relevance of the inclusion of 'local jargon' in a SMM. Some (35\%) of the respondents indicated it as "rarely relevant", although the majority (54\%) were of the view it was "significantly relevant". Consequently this characteristic would be given less weight in developing a SMM.

The Z-Test yielded p-values of approximately zero for all the characteristics except 'regional relevance' and 'inclusion of local jargon'. This implied that apart from these two characteristics, there was almost $100 \%$ certainty that all quantity surveyors would hold the opinion that the other characteristics were relevant and should be exhibited by an SMM. Considering 'regional relevance', the Z-Test yielded a $p$-value of 0.01 , which implied there was a $99 \%$ certainty that the respondents will rate this property as "significantly relevant". In the case of 'inclusion of local jargons', the pvalue was 0.88 which implies there was only $12 \%$ certainty that quantity surveyors would indicate that local jargon should be included in an SMM. Therefore considering a 5\% significance level (i.e. 95\% confidence level), all the characteristics were accepted as "significantly relevant" except 'inclusion of local jargon'.

\begin{tabular}{|c|c|c|c|c|c|c|c|c|c|c|c|c|c|c|}
\hline \multirow[b]{2}{*}{$\begin{array}{l}\text { Analytical } \\
\text { Statistics }\end{array}$} & \multicolumn{14}{|c|}{ Characteristics of SMM (variables) } \\
\hline & 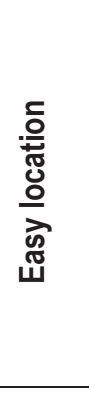 & 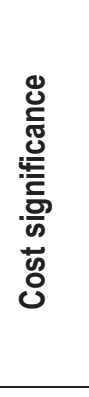 & 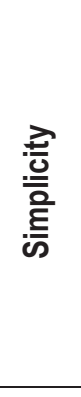 & 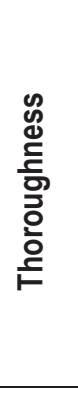 & 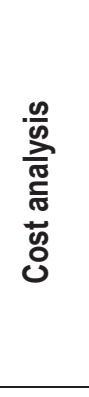 & 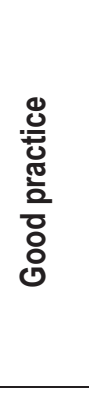 & 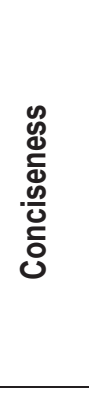 & 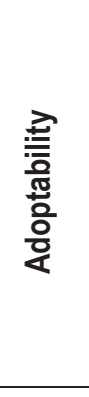 & 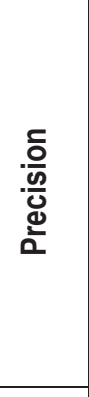 & 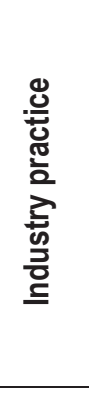 & 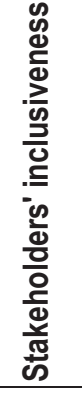 & 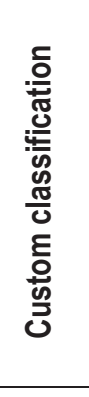 & 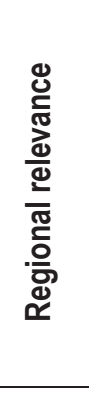 & 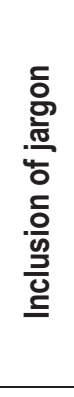 \\
\hline Mode & 1 & 1 & 1 & 1 & 1 & 2 & 2 & 2 & 1 & 2 & 2 & 3 & 3 & 4 \\
\hline $\begin{array}{l}\text { Mode } \\
\text { frequency }\end{array}$ & 75 & 60 & 60 & 60 & 51 & 48 & 48 & 48 & 42 & 42 & 48 & 60 & 45 & 39 \\
\hline $\begin{array}{l}\text { Rating } \leq \\
\text { moderate } \\
\text { (Frequency) }\end{array}$ & 111 & 108 & 108 & 108 & 108 & 111 & 111 & 105 & 99 & 102 & 102 & 99 & 90 & 60 \\
\hline $\begin{array}{l}\text { Total } \\
\text { Response }\end{array}$ & 111 & 111 & 111 & 111 & 111 & 111 & 111 & 111 & 108 & 111 & 111 & 108 & 111 & 111 \\
\hline$\%$ Mode & $68 \%$ & $54 \%$ & $54 \%$ & $54 \%$ & $46 \%$ & $43 \%$ & $43 \%$ & $43 \%$ & $39 \%$ & $38 \%$ & $43 \%$ & $56 \%$ & $41 \%$ & $35 \%$ \\
\hline $\begin{array}{l}\% \text { Rating } \leq \\
\text { moderate }\end{array}$ & $100 \%$ & $97 \%$ & $97 \%$ & $97 \%$ & $97 \%$ & $100 \%$ & $100 \%$ & $95 \%$ & $92 \%$ & $92 \%$ & $92 \%$ & $92 \%$ & $81 \%$ & $54 \%$ \\
\hline Mean & 1.37 & 1.56 & 1.59 & 1.64 & 1.75 & 1.81 & 1.86 & 1.94 & 2.00 & 2.05 & 2.24 & 2.67 & 2.73 & 3.13 \\
\hline $\begin{array}{l}\text { Average } \\
\text { deviation }\end{array}$ & 0.51 & 0.61 & 0.64 & 0.70 & 0.69 & 0.61 & 0.60 & 0.66 & 0.77 & 0.72 & 0.74 & 0.70 & 0.91 & 1.01 \\
\hline $\begin{array}{l}\text { Interpretation } \\
\text { of mode }\end{array}$ & high & high & high & high & high & very & very & very & high & very & very & mod & mod & rare \\
\hline$p$-value & 0.00 & 0.00 & 0.00 & 0.00 & 0.00 & 0.00 & 0.00 & 0.00 & 0.00 & 0.00 & 0.00 & 0.00 & 0.01 & 0.88 \\
\hline
\end{tabular}

Key to Likert scale: 1 = highly relevant; 2 = very relevant; 3 = moderately relevant; 4 = rarely relevant; 5 = irrelevant

Table 3 Analysis of Survey Response Ratings of Essential properties of an SMM. 


\section{CLASSIFYING THE DESIRED CHARACTERISTICS OF A SMM}

Based upon their mean scores in the analysis (Table 3 ), the desirable characteristics of a SMM were grouped into bands of 'highly essential', 'very essential', moderately essential' and 'rarely essential' (Table 4). These bands could be used as criteria for evaluating SMMs (or SMM amendments/ revision) for their 'fitness for purpose'. Minor shifts in the composition of these 'characteristics bands' may be expected from one region to the other since technology, culture and legal framework differ from one region to the other. It is therefore necessary to adequately address any regional differences, and regroup the characteristics in order to apply them in countries other than Ghana.

\section{CONCLUSIONS}

A study of various SMMs (in respect of the rationale for their development and revision), a review of critiques to measurement standards, and an exploration of local measurement practices in Ghana, formed the basis for establishment of the desirable and essential characteristics of SMMs.
Ghana has adopted the UK SMM5 as a standard for measurement but with modifications. These modifications can be grouped into seven categories: 'cost insignificant items'; 'minor labour items'; 'customary units of measurement'; 'method related items'; 'combinable items'; 'subordinate items'; and 'items of minor informative impact'. All groups of modifications were relevant and acceptable to quantity surveyors in Ghana except for the elimination of 'items of minor informative impact'. All these modification types should be considered in SMM development or revision.

Certain SMM characteristics such as 'ease of locating items', 'attention for cost significance', 'simplicity', 'thoroughness', and 'cost analysis' are considered desirable for a good SMM.

SMMs are based on the prevailing state of technology, industry culture, and legal framework, which often differ from one region to the other, so the relevance and desirability of the SMM characteristics can be expected to vary between regions.

\begin{tabular}{|l|l|}
\hline Characteristic to Assess & Explanation of Characteristic \\
\hline GROUP A (Highly Essential Properties) \\
\hline Easy location & Easy to locate work items and rules. \\
\hline Cost significance & Consideration for cost significance of items. \\
\hline Simplicity & Simple to use (uncomplicated). \\
\hline Thoroughness & Thorough (logical inclusion of all work). \\
\hline Cost analysis & Consideration for subsequent cost analysis purposes. \\
\hline GROUP B (Very Essential Properties) \\
\hline Good practice & Based on essentials of good practice. \\
\hline Conciseness & Concise (avoid unnecessary detail). \\
\hline Adoptability & Adoptability to all procurement systems. \\
\hline Precision & Precise (rules not open to multiple interpretations). \\
\hline Industry practice & Based on existing industry practice. \\
\hline Stakeholders (Moderately Essential Properties) \\
\hline GROUP C & Coccommodation for custom classification. \\
\hline Custom classification & Regional (Ghana) relevance. \\
\hline Regional relevance \\
\hline GROUP D (Rarely Essential) \\
\hline Inclusion of jargon & Consideration for local jargon / terms. \\
\hline
\end{tabular}

Table 4 Relative importance of desirable qualities of a SMM 


\section{REFERENCES}

ACE and RICS (1984) Standard Method of Measurement for Industrial Engineering Construction, London, The Association of Cost Engineers and the Royal Institution of Chartered Surveyors.

AIQS (2001) Standard Method of Measurement for Building Works, 5th ed., Canberra, Australian Institute of Quantity Surveyors and Master Builders Incorporated.

AIQS and MBFA (1980) Australian Standard Method of Measurement of Building Works, Brisbane, Australian Institute of Quantity Surveyors and Master Builders' Federation of Australia.

Architectural Association of Kenya (1996) Standard Method of Measurement of Building Works, 2nd ed., Nairobi, Architectural Association of Kenya: Chapter of Quantity Surveyors.

ASAQS (1977) Standard System of Measuring Builders' Work, 5th ed., South Africa, Association of South African Quantity Surveyors and Building Industries Federation (South Africa).

ASAQS (1999) Standard System of Measuring Building Work, 6th ed., Johannesburg, The Association of African Quantity Surveyors.

Badu, E., Amoah, P. and Gyamfi, G. F. (2004). Risk sharing in Ghanaian construction contracts. the Ghanaian surveyor, 1, 1- 12.

BCIS (2004) Measurement Based Procurement of Buildings: A Survey of Who Measures Buildings. RICS Measurement Conference. Royal Institution of Chartered Surveyors.

Brook, M. (2004) Estimating and tendering for construction work, Boston, Elsevier Butterworth-Heinemann.

Bureau of Indian Standards (1987) Handbook of Method of Measurement of Building Works, 1st Ed. : SP 27: 1987, Bureau of Indian Standards.

Clarke, G. M. and Cook, D. (1998). A Basic Course in Statistics, $4^{\text {th }}$ edn, New York, Arnold.

Dansoh, A. and Akyempim, N. K. O. (2004). Key factors in strategic planning decisions of contractors in Ghana The Ghanaian Surveyor, 1, 22-27.

Djakumah, D. (2004) Abridging the 7th edition of the Standard Method of Measurement of
Building Works to suit the Ghanaian construction practices- Cladding/covering section, BSc. Project Building Technology Department. Kumasi, Kwame Nkrumah University of Science and Technology.

Dodoo, A. (2003) Abridging the 7th edition of Standard Method of Measurement of Building Works to suit the Ghanaian construction practices- Groundworks section. Building Technology Department. Kumasi, Kwame Nkrumah University of Science and Technology.

Earley, M. and Gould, H. F. (2004) Current Topic: Standard Method of Measurement. Accessed at: www.rics.org.

Edwards, P. J. and Edwards, M. (1995) A price - rationalized approach to item separation in the measurement of concrete work. Construction Management and Economics, 13(6), 485 - 491.

Foster, C. (2005) Mechanical and electrical measurement - do the rules need changing? Accessed at www.rics.org.

Goh, B. H. and Chu, Y. L. (2002) Developing National Standards for the Classification of Construction Information in Singapore. International Council for Research and Innovation in Building and Construction CIB W78 conference 2002. Aarhus School of Architecture, 12 - 14 June.

Hanson, G. (2003) Abridging the SMM7 to suit Ghanaian construction practices (Section E In situ Concrete/Large pre-cast concrete), BSc Project. Building Technology Department. Kumasi, Kwame Nkrumah University of Science and Technology.

Hohoabu, K. (2003). Factors influencing bidno-bid decisions of contractors in Ghana ,. The Ghanaian Surveyor, 1, 11-22.

Horner, M. and Zakieh, R. (1996) characteristic items - a new approach to pricing and controlling construction projects. Construction management and Economics, 14, 241-252.

ICE (1968) Standard Method of Measurement of Civil Engineering Quantities. Institute of Civil Engineers, London.

ICE (1991) Civil Engineering Standard Method of Measurement, London, Thomas Telford.

Jaggar, D., Ross, A., Love, P. E. D. and Smith, S. (2001) Overcoming information opacity in construction: a commentary. Logistic Information Management, 14, 413-421. 
Kumar, R. (1999). Research methodology: A step-by-step guide for beginners, London, SAGE Publications.

Laate, R. N. (2003) Abridging the 7th edition of Standard Method of Measurement of Building Works to suit the Ghanaian construction practices - Masonry section. Building Technology Department. Kumasi, University of Science and Technology.

Mills, A., Lawther, P. and Jones, D. (2006) Standard Methods of Measurement - A Comparative Study of National and Regional Publications. Australian Institute of Quantity Surveyors and Royal Institution of Chartered Surveyors

Morledge, R. and King, S. (2005) The effectiveness of current pricing documentation from the perspective of the contractor's estimator. CIB W92/ T23/W107 International symposium on procurement. NY USA.

Nanai G. and Adjei-Kumi, T. (2007) Challenges of quantifying construction work for control processes in Ghana, International Council for Research and Innovation in Building and Construction CIB World Building Congress 2007. Cape Town, South Africa, 14 -17 May.

NIQS (2003) Building and Engineering Standard Method of Measurement, 2nd ed., Lagos, Nigerian Institute of Quantity Surveyors.

RICS (1979) Principles of Measurement (International) for Works of Construction, London, Royal Institution of Chartered Surveyors.

RICS (2003) Standard methods of measurement in current use, International Survey. Accessed www.rics.org/faculty/construction.

RICS and BEC (1988) Standard Method of Measurement for Building Works, 7th ed., London, Royal Institution of Chartered Surveyors and Building Employers Confederation.

RICS and BEC (1998) Standard Method of Measurement for Building Works, 7th ed., London, Royal Institution of Chartered Surveyors and Building Employers Confederation.

RICS and NFBTE (1964) Standard Method of Measurement of Building Works, 5th ed., London, Royal Institution of Chartered Surveyors and National Federation of Building Trades Employers,.
RIDER HUNT (1988) Rider Hunt System of Measurement for Construction Quantities, 1st ed., Brisbane, Rider Hunt.

SISV (1986) Singapore Standard method of Measurement of Building Works, 2nd ed., Singapore, Singapore Institute of Surveyors and Valuers.

SPRING (2002) Code of Practice for Construction Electronic Measurement Standards (CEMS) - Part 1: Standard Method of Measurement (SMM) for Building Works, Singapore, SPRING Singapore.

Tas, E. and Yaman, H. (2005) A building cost estimating model based on cost significant work packages. Engineering, Construction and Architectural Management, 12(13), 251 - 263.

Wood, B. and Kenley, R. (2004) The Effectiveness of the Bills of Quantities in Australia. Journal of Construction Research, 5, 291-309. 